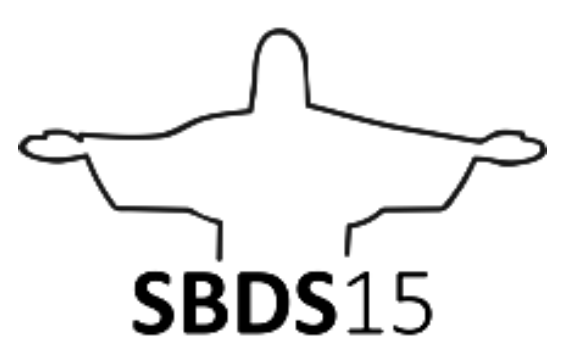

5 SIMPÓSIO DE DESIGN SUSTENTAVELL

\title{
CENÁRIOS FUTUROS COMO FERRAMENTA PARA A ORGANIZAÇÃO DA SOCIEDADE CIVIL
}

\author{
Isabel Cristina d'Avila Oliveira \\ Unisinos \\ i.davila@terra.com.br \\ Karine de Mello Freire \\ Unisinos \\ kmfreire@unisinos.br
}

\begin{abstract}
Resumo: Este artigo descreve o modelo de "Cenários Transformadores" pela perspectiva do design estratégico. Objetiva entender a contribuição da ferramenta para a estratégia de atuação da sociedade civil na proposição de políticas públicas. Para tanto, o trabalho investiga a capacidade dos representantes das organizações da sociedade civil em absorver as práticas dos cenários e utilizar da tecnologia dessa ferramenta para o avanço na condução de suas estratégias. Apresenta o exercício do "Cenários Sociedade Civil 2023", ocorrido no Brasil entre 202 e 2013, que serviu de objeto de estudo para a análise das possibilidades de conceber uma solução própria às organizações da sociedade civil que atuam no contexto das políticas públicas.
\end{abstract}

Palavras-chave: design estratégico, inovação social, cenários, sociedade civil

\begin{abstract}
This article describes the "Transformers Scenarios " model for the strategic design perspective. Aims to understand the tool's contribution to civil society operating strategy in proposing public policies. Thus, the study investigates the ability of representatives of civil society organizations to absorb the practices of scenarios and make use of this technology tool for advancing in the conduct of their strategies. It presents the exercise of "Scenarios Civil Society 2023", held in Brazil between 2012 and 2013, which was the object of study to analyze the possibilities of conceiving their own solution to civil society organizations working in the context of public policy.
\end{abstract}

Keywords: strategic design, social innovation, scenarios, civil society 


\section{INTRODUÇÃO}

Em artigo no qual trata da sua prática de designer para facilitar projetos de co-criação entre órgãos do governo dinamarquês e atores civis, Bason (2010) defende a ideia de que o crescimento da turbulência do sistema social pode ser o motivo do alargamento do trabalho de design na esfera pública. O autor aponta a satisfação dos usuários e a racionalização dos processos entre os benefícios alcançados pelos projetos design orientados e os indica como categorias possíveis de serem mensuradas a fim de identificar a efetividade destes. Por fim, relata casos de serviços totalmente modificados, nos quais foram conduzidas experiências positivas de co-criação. Para Bason, a abordagem criativa dos projetos de inovação social conduzidos pelos designers permite aos governos projetar formas de combater os desafios perversos da estrutura social, indo além das soluções adotadas rotineiramente.

Manzini (2008) defende a necessidade dos designers assumirem seu papel de facilitadores quando atuam em propostas cujo objetivo é "mudar a mudança". Entendendo-se por mudança o desenvolvimento de projetos que atendam às tendências de economia verde, economia em rede e inovação social, trazendo propostas articuladas e com força para mudar os paradigmas da sociedade até agora baseada na produção e no consumo.

Uma contribuição do design estratégico nos processos organizados da sociedade civil está em suportar a materialização de serviços e produtos, considerando os objetivos das organizações e dos demais atores que atuam junto a elas na construção de cenários futuros. Descritos por Manzini (2007) como a ferramenta mais estratégica à disposição dos designers, os cenários oportunizam espaço para reflexão e geram estímulos à construção de visões compartilhadas. Segundo o autor, é pela construção de cenários que se torna possível quebrar a ideia dominante e altear o rumo em sentido a uma proposição de soluções totalmente novas para o funcionamento do sistema. Para o autor, os cenários são uma conversa estratégica entre os grupos da sociedade (MANZINI, 2010). Como enfatiza Drucker (2010), a elaboração de estratégias bem definidas possibilita às organizações a agilidade para repensar os objetivos e redirecionar os caminhos, adotando uma visão de longo prazo no lugar de pequenos planejamentos calcados em visões de curto prazo.

Este artigo aborda os temas relativos ao design estratégico quando de sua aproximação com a sociedade civil na condução de projetos para a proposição de políticas púbicas, utilizando a ferramenta de cenários futuros. Para tanto, aborda o modelo de "Cenários Transformadores", desenvolvido por Adam Kahane nos anos de 1980 e aplicado em governos e vários países pelo REOS Partners, instituto criado e presidido por ele. Apresenta os resultados da pesquisa feita entre 2014 e 2015, no estudo dos "Cenários Sociedade Civil 2023".

\section{DESENVOLVIMENTO}

É inconcebível admitir que, frente aos novos desafios impostos pela falência iminente dos recursos ambientais, aos novos modelos econômicos resultantes da globalização e à estrutura social impactada pelo uso da rede virtual, sejam aplicadas antigas soluções. A crescente complexidade dos problemas levou representantes dos setores públicos, privados e da sociedade civil organizada a perceber a importância de fortalecer as conexões dos atores em redes presenciais ou virtuais, no intuito de alcançar os objetivos que contemplam benefícios comuns (CASTELLS; INCE, 2003; 2013a; MANZINI, 2010).

Encontrando novos espaços de atuação, os designers expandem e diversificam sua atividade, chegando às organizações do terceiro setor, aos governos e às comunidades informalmente constituídas, vislumbrando os recursos sociais que podem ser utilizados na proposição de projetos socialmente inovadores. Para Margolin (1996, p. 48), "quando o design não se limita a produtos materiais, os designers podem influir nas organizações e nas situações de diversas maneiras". A proposta de Margolin é pensar a atuação do designer, refletindo como ele pode projetar produtos e serviços de uma maneira a não ser mais um agente da 
degradação dos recursos do planeta. O autor observa que esses profissionais devem buscar a habilidade de demonstração, que ele refere como "arte da demonstração" (MARGOLIN, 1996, p. 48), para conciliar os aspectos da expansão com os aspectos da atenção ao esgotamento do modelo de consumo indiscriminado. Assim, o design dentro das organizações passa também a representar um espaço de questionamento dos modelos dos processos.

A inovação social ${ }^{1}$ vista no sentido botom up, de iniciativa da sociedade civil, articulouse mais fortemente nas últimas duas décadas, movida em grande parte por decisões focadas na melhoria do desenvolvimento urbano. Destacam-se o projeto SusHouse2, financiado pela União Europeia, e o Sustainable Everyday3, financiado pela UNEP - United Nations Environment Program (MANZINI; JÉGOU, 2003). Florescem projetos de cidadãos interessados no cuidado e ocupação consciente dos espaços públicos, em ações com maior ou menor grau de inovação, mas sempre orientadas no sentido de empoderamento da pessoa. Porém, os projetos inovadores da sociedade civil passam a depender também da participação direta do governo sempre que os temas exigirem a promoção de políticas públicas em forma de programas e leis e da disponibilização de serviços públicos. (MANZINI; STASZOWSKI, 2013).

$\mathrm{Na}$ definição desses problemas e, especificamente, nos de políticas públicas ${ }^{4}$, a sociedade e governos vêm se aproximando para juntos conduzir os temas em que compartilham interesse (RUA, 2001). De um lado, a sociedade civil vem abandonando o preconceito em fazer parte dos grupos de trabalho do governo e se aproxima deste para a criação de novos serviços ou políticas. Do outro, o setor público começa a ver o cidadão não mais como um problema a ser atendido e, lentamente, incorpora suas expectativas na construção dos projetos. Esse movimento híbrido, do governo para a sociedade, e vice-versa, abre espaço para a cultura de design e propostas potencialmente mais inovadoras (BASON, 2010). O limite do design, nesses casos, está na dificuldade de resolver problemas de macroescala, com alta complexidade e integrados a uma rede atingida também por outras questões estruturais.

Para compreender essas novas questões que chegam aos projetos, o design se articula a outras áreas - na condição de disciplina integrativa -, no intuito de agregar conhecimentos e práticas, como Antropologia, Sociologia, Serviço Social, entre outras, que contribuem com as visões das suas práticas e cultura. Nesse mix, o que surge é um design estratégico, no qual os aspectos dos serviços e dos significados prevalecem sobre o desenvolvimento de produtos (BUCHANAN, 1992; MARGOLIN e MARGOLIN, 2004; MERONI, 2008).

Frente à perspectiva de uso das ferramentas de design para processos de inovação social na proposição de políticas públicas, e do pensamento de Manzini, de que os cenários são a mais completa ferramenta estratégica do design, pesquisaram-se métodos de cenários que atendessem a essas premissas. Foi identificado o "Cenários Transformadores", desenvolvido pela REOS Partners, com inspiração na cultura de projeto, especialmente nos conceitos de inovação, co-criação e visualização. Os "Cenários Transformadores" são propostos no sentido top-down, partindo da identificação, pelo Estado, da necessidade de trazer soluções

\footnotetext{
${ }^{1}$ Na publicação da Young Foundation ${ }^{1}$, de 2010, inovação social é definida como "novas ideias (produtos, serviços e modelos) que atendam simultaneamente às necessidades sociais e criem novas relações ou colaborações sociais". (MURRAY; CAULIER-GRICE; MULGAN, 2010, p. 9

2 SusHouse é um projeto de pesquisa financiado pela União Europeia (1998-2000) preocupada em desenvolver e avaliar estratégias de transição para famílias sustentáveis. O objetivo do projeto é cumprir funções de uso doméstico, de uma maneira que é 20 vezes mais eficiente, para o ambiente no futuro (Factor 20) até ao ano 2050.

${ }^{3} \mathrm{O}$ livro é o resultado de um programa de pesquisa internacional. Ele traça um cenário detalhado da vida cotidiana sustentável.

${ }^{4}$ De maneira geral, pode-se dizer que as políticas públicas resultam das diretrizes adotadas pelo poder público, traduzindo-se em políticas de governo ou políticas de Estado. Compostas por um conjunto de regras e procedimentos, definem a maneira como se dão as relações entre poder público e sociedade, expressas em forma de projetos e/ou concebidas pela formulação de leis. (TEIXEIRA, 2002).
} 
inovadoras a questões de caráter estruturante da política nacional e reúnem representantes de todos os setores, direta ou indiretamente envolvidos.

O objeto de estudo é o "Cenário Sociedade Civil 2023". O objetivo é compreender a arquitetura dos "Cenários Transformadores" e identificar os pontos favoráveis e desfavoráveis do uso da ferramenta para o desenvolvimento de projetos estratégicos nas organizações da sociedade civil. A pesquisa partiu da identificação da lacuna do desenvolvimento dessas ferramentas, ao mesmo tempo em que se evidencia o crescimento em número e influência política das organizações.

O tema escolhido ainda é pouco explorado: a utilização da ferramenta de cenários de design pelas organizações da sociedade civil, quando do estabelecimento de estratégias para a proposição de políticas públicas. Considerando o pouco volume de informações, a intuição do pesquisador pode determinar o acerto, ou não, na direção das escolhas para a coleta das informações. Apesar de não haver experiências documentadas a respeito de cenários construídos em uma organização da sociedade civil brasileira, o "Cenário Sociedade Civil 2023", desenvolvido nos anos de 2012-2013, contém alguns elementos próprios a essa demanda: tem $40 \%$ da equipe composta por organizações da sociedade civil, os objetivos principais são relativos à atuação dessas organizações no quadro político brasileiro, a pauta refere-se diretamente à proposição do marco legal das organizações da sociedade civil e tem grande parte do moelo orientado pelas capacidades de design de Zurlo (ver, prever, fazer ver) e as capacidades humanas da criatividade e inovação (MANZINI, 2010).

Os métodos escolhidos para subsidiar os objetivos deste trabalho foram: pesquisa documental; pesquisa bibliográfica; observação participante; entrevistas semiestruturadas em profundidade, com sete participantes do exercício, representantes das organizações. ${ }^{5}$

\section{CENÁRIOS TRANSFORMADORES: bases conceituais}

Com o pensamento "conte novas histórias e nos habilite a criar novos futuros", Adam Kahane (2013) sintetiza o que entende ser a essência do trabalho de construção de cenários. Fundamentalmente, a característica do trabalho de cenários está focada em desconstruir os modelos mentais e expor ideias com narrativas que operam nos domínios do entendimento do que acontece no panorama do sistema. Os principais resultados, no entendimento de Kahane, relacionam-se às relações e às intenções, especialmente em situações que se caracterizam pela alta complexidade social, conflitos extremos e fragmentação nos relacionamentos entre os atores. $O$ ponto alto do cenário é compreender as intenções não claramente expressas nos relacionamentos e viabilizar o estreitamento do diálogo de forma a habilitar os atores a lançar ideias novas na tentativa de tornar as circunstâncias futuras mais positivas do que as atuais.

No momento histórico em que os "Cenários Transformadores" foram desenvolvidos, o desafio era tornar possível o diálogo entre representantes de setores com profundas cisões políticas e culturais. Para "oxigenar" a discussão, a sugestão de Kahane foi montar a equipe com pessoas "fora da caixa" (KAHANE, 2013), aquelas que criariam o ruído necessário para fazer as demais olharem a situação nacional de maneira alternativa. Segundo o autor, o diálogo foi favorecido pela forma como o tema foi encaminhado: as opiniões expressas deveriam identificar o que as pessoas acham que acontecerá no futuro, e não o que elas gostariam que acontecesse. Nos Cenários Transformadores a pergunta é: o que se pode fazer para construir um novo futuro a partir do que se constata?

Os instrumentos mais utilizados no mapeamento sistêmico são workshops, mapa de atores, prototipagem e matriz SWOT. Das condições necessárias para o sucesso do trabalho, o autor chama a atenção sobre as capacidades indispensáveis dos facilitadores designers) e da

\footnotetext{
${ }^{5}$ Ao total, participaram 35 organizações, órgãos públicos e universidades. Entre elas: Secretaria Geral da Presidência da República, Instituto C\&A, Instituto Unibanco, Fundação Avina, Movimento Nacional de Catadores de Materiais Recicláveis, Quebradeiras de Coco Babaçu, Grupo de Institutos Fundações e Empresas - GIFE.
} 
equipe em geral. A ferramenta requer que os participantes tenham a capacidade de representar, pela aplicação das técnicas e instrumentos utilizados, uma variedade de ideias e perspectivas de forma clara e precisa. A condução dos trabalhos deve ajudar as pessoas a fazerem a diferença juntas, acima de tudo, ter comprometimento e vontade de trabalhar com os demais. Organizar, suportar e facilitar as pessoas para encontrarem uns aos outros e, dessa forma vislumbrar o caminho a seguir e as capacidades necessárias para trabalhar em prol de sua construção.

Cabe ao facilitador ser intencional e flexível, de modo a equilibrar a ação e a reflexão da equipe; receber a tensão e ambiguidade das relações do grupo, para auxiliar na transposição para a etapa de ajustes das ideias e construção do relatório elaborado a partir do entendimento de todos. Os que permanecem após a fase de apresentação dos cenários devem constantemente adaptar o projeto para atender a situações específicas não consideradas inicialmente e que vão surgindo ao longo do tempo. Também compoem a equipe os convocadores, que são os participantes do grupo propositor e organizador do cenário e os participantes representates das organzações que completam o grupo e aos quais cabem responder as pesquisas, participar dos workshops e divulgar o relatório final.

\section{1 cenários "SOCIEDADE CIVIL 2023": um exercício executado no Brasil}

O trabalho da construção dos 'Cenários Sociedade Civil 2023' começou em 2012 com a reunião dos representantes convocadores, pertencentes a Aliança D3, fomada por alguns dos maiores institutos e fundações atuantes no Brasil; a SGPR (Secretaria Geral da Presidência da República); e a REOS Partner, instituto criado por Kahane para aplicar essa e outras ferramentas para projetos de inovação social junto a governos de vários países.

O grupo definiu os critérios para a escolha dos participantes: movimentos representando as cinco regiões do Brasil; e diversidade de temas, considerando os que vêm obtendo mais destaque no país, contemplando as causas de caráter social e ambiental. Por fim, para cada escolhido foi identificado o representante com atuação destacada e a este foi enviado o convite nominal e intransferível. Foi executada a fase de levantamento das insformações sobre o tema do exercício do cenário e as entrevistas-diálogo com todos os representantes das organizações que iriam fazer parte dos workshops.

A fase dos workshops deu início a uma série de dinâmicas que proporcionam o que se chama de diálogo estratégico. Meroni (2008) trata desse tema ao abordar a atividade de design estratégico. Para a autora, toda prática que induz a algum tipo de reflexão do grupo, como o contrabriefing e o codesign, produz um diálogo com perfil estratégico. Ocorreram dois workshops, em encontros de dois dias cada. No primeiro, foram aprofundados os diálogos para identificação da agenda estratégica. Em seguida, foram levantadas as forças motrizes6 e classificadas nos eixos de previsibilidade e impacto. Na seqüência, foram destacadas as forças de maior impacto, que constarão na elaboração de todos os cenários.

É possível analisar a etapa da criação dos cenários por dois conceitos usados no design: co-criação e visão convergente. No primeiro, os atores participam ativamente na concepção da ideia e há troca de experiências considerando a mescla dos diversos repertórios individuais. Como afirma Kingsley (2009 apud MOUCHREK; KRUCHEN, 2014), "co-criação / codesign é uma forma de progredir a partir de um problema ou cenário e é usado, por exemplo, para promover mudanças de necessidade de haver uma identidade comum entre os participantes. As visões convergentes estão diretamente associadas à noção de identidade comum. Para Manzini (2010), só é possível haver sintonia entre os participantes do grupo se há identificação entre eles, pois a interpretação de um dado é resultado da construção cultural dos atores.

\footnotetext{
${ }^{6}$ Podem ser sociais, tecnológicas, ambientais, econômicas e políticas, existem no contexto em que a sociedade civil organizada se encontra. Qualquer mudança em uma força motriz pode ter grande impacto nos temas da agenda estratégica. (Relatório Sociedade Civil 2023, p. 6).
} 
Nesse momento do exercício os atores com concepções semelhantes são chamados a se aproximarem, pois agora o esperado é um diálogo encaminhando para a solução do problema e com o qual todos devem se sentir comprometidos.

O relatório dos cenários foram descritos em formato de storytelling, adicionados textos explicativos dos conceitos e dos temas tratados, somados depoimentos retirados das entrevistas diálogo e desenhos ilustrativos do teor de cada cenário concebido. As informações devem auxiliar na clareza sobre os fatos do contexto atual e dos pontos de vista resultantes do trabalho da equipe.

Basicamente, os cenários "Sociedade Civil 2023" foram um exercício de reflexão sobre a relação da sociedade civil organizada com o Estado, a sustentabilidade econômica das organizações e os novos modelos de certificação para ampliar a capacidade de oficialização de organizações alijadas dos benefícios estatais.
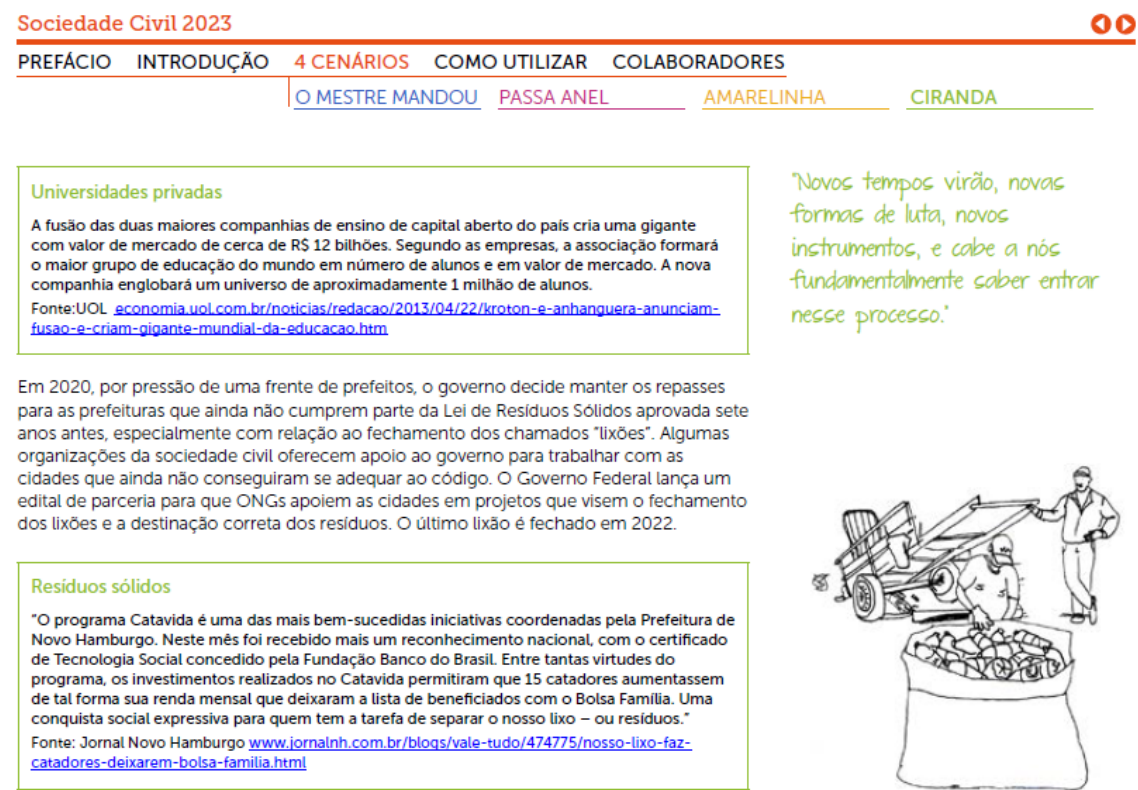

Figura 8 - Exemplo da apresentação dos cenários Sociedade Civil 2023

Fonte: Relatório Sociedade Civil 2023

\section{ANÁLISE DO EXERCÍCIO DOS “CENÁRIOS SOCIEDADE CIVIL 2023”}

A partir da pesquisa documental, bibliográfica, da observação participante e das entrevistas, pôde-se destacar as categorias de análise nas quais se identificou o grau de validade da ferramenta para a ação estratégica da sociedade civil na proposição de políticas públicas. Foram separadas em dois blocos: o primeiro trata das dimensões afetadas pelo trabalho: representante, organização, o grupo de trabalho. $O$ segundo trata das forças que afetam a qualidade das relações e o resultado final, que são relações de poder, participação e visualidade.

\section{1 dimensão do representante}

Alguns entrevistados citaram a dificuldade inicial de compreender o que era esperado de sua participação e o objetivo final do trabalho. Por outro lado, a maioria dos entrevistados que relatou o momento de estranheza também mencionou o posterior entendimento da finalidade da constituição do grupo de trabalho. No tocante aos representantes da sociedade civil, principalmente os de menor porte ou com menor possibilidade de acesso, a retomada do cotidiano e o afastamento do trabalho dos cenários acaba por afastá-los do processo e enfraquecer a possibilidade de influir na fase de divulgação do trabalho. 
O depoimento dos convocadores e do grupo em geral refere-se ao benefício da aproximação com um perfil de atores, impensável na prática diária. Para muitos, o mais importante foi ter a oportunidade de conhecer realidades distintas das suas, enxergando o benefício da troca de experiências e da possibilidade de manter, mesmo informalmente, um espaço de discussão e diversidade de ideias. Questionados se a participação neste trabalho influenciou a mudança de posicionamento, é necessário que se faça uma distinção temporal. Num primeiro momento, se se referir estritamente à mudança de modelo mental ao longo das dinâmicas de construção de cenários, o relato dos participantes revela a aceitação das diferenças e da visualização de futuros impensáveis antes do início do trabalho.

\section{2 dimensão da organização representada}

A repercussão junto às organizações dos convocadores e dos demais representantes foi pequena frente ao envolvimento pessoal. Um primeiro nível de repercussão esperada seria no tratamento dos temas discutidos nos cenários junto aos componentes das organizações. Nesse caso, a maioria dos entrevistados das organizações da sociedade civil relatou a dificuldade de tempo para reportar o que havia vivenciado no trabalho e a dificuldade de agenda interna para essa pauta. Entre os convocadores, o acompanhamento do trabalho dos cenários possuía pelo menos mais um acompanhamento interno. $O$ tamanho das organizaçõe é uma diferença significativa entre essas categorias de representantes. Os convocadores, em sua maioria, vêm de fundações ligadas a empresas de grande porte ou são estruturas internacionais de financiamento de projetos socioambientais. Nesses casos, apesar de nascerem em grandes empresas, são geridos por pequenos escritórios, com poucos funcionários, o que facilita a troca de informações. As demais organizações têm representantes de todos os portes, mas em geral possuem ramificações em mais de uma localidade, ou são formadas por voluntários, o que afeta a capacidade de divulgar informações e dificulta a disseminação dos aprendizados e a consequente influência destes na consução da organização.

Questionados sobre a possibilidade de aplicar um exercício de cenários em sua organização com os stakeholders, em outras questões de interesse a resposta geral foi negativa. Entre os convocadores, muitos já têm ferramentas de planejamento estruturadas e mudar o sistema implica tempo e investimento financeiro injustificado. Para as demais organizações, o trabalho com cenários é totalmente impensado, pelo alto nível de conhecimento específico demandado. Os representantes, apesar de considerarem o aproveitamento da experiência, não conseguem visualizar claramente o uso da ferramenta para a sua realidade.

\section{3 dimensão do grupo}

Os representantes reconhecem a coordenação eficiente das atividades e a qualidade na condução das dinâmicas. De acordo com um dos entrevistados, a convivência não foi muito longa, mas suficiente para entender os princípios da criação coletiva e do pensamento por cenários. Destacam-se duas características que impactam positivamente na composição do grupo.

Um retorno indireto verificado foi o reconhecimento dos atores no que diz respeito ao papel e às contribuições de cada um ao longo do processo. Isso é especialmente valorizado nas dinâmicas, principalmente nas entrevistas-diálogo e na confrontação de posições prós e contras. O modo como acontecem as manifestações dos participantes vai imprimindo a arquitetura da identidade do grupo. Para Castells (1999), a construção da identidade é consequência das informações do ambiente, em que os significados são reorganizados pelos indivíduos e pelos grupos. Ela ocorre em contextos marcados pelas relações de poder, portanto, a identidade assumida pela equipe participante do cenário resulta das forças dominantes manifestas entre eles. 
A ferramenta prevê esse embate e usa recursos sensoriais e dinâmicas como uma maneira de baixar a tensão entre essas forças e permitir a formação da identidade o mais análogo possível à contribuição de cada um. Ao longo da atividade, é esperado que se constitua um "corpo" com uma identidade revelada na escrita do relatório e na continuidade das atividades, em debates externos e participações em outras instâncias posteriores.

\section{4 relações de poder}

Quanto à influência política dos representantes ao longo de todo o processo de cenários, é importante proceder a uma separação em três macroetapas: a primeira é a decisão pelo uso dessa ferramenta e a definição da equipe de trabalho; a segunda é a atividade de construção de cenários, efetivamente; e a terceira é a divulgação e discussão para aprofundamento do tema. Apesar da solidez no desenvolvimento da ferramenta para o controle das forças políticas representadas, nem toda a influência de poder pode ser controlada, visto que definição do tema e a seleção dos participantes são controlados pelos representantes dos convocadores. A despeito de haver uma clara hierarquia nessas etapas, na construção dos cenários esse desnível da posição política dos representantes torna-se mais imperceptível ao longo dos workshops.

A redação final do relatório é outro momento em que aparece a tentativa de imposição do poder de alguns representantes das organizações. A equipe dessa etapa do trabalho era formada basicamente por atores com atividade de caráter político, o que pode ser fator importante para reavivar essa postura.

\subsection{Participação}

$\mathrm{Na}$ formação dos convocadores, a equipe possuía caráter mais homogêneo. Nesta etapa, reuniram-se institutos, fundações, órgãos governamentais, enfim, financiadores e/ou detentores de algum nível de decisão sobre os encaminhamentos das políticas relacionadas às organizações sociais brasileiras. Essa homogeneidade firmou a construção da identidade coletiva desses representantes. Castells (1999) identifica esse modelo como identidade coletiva legitimadora formada pela sociedade civil e que, segundo o autor, "reproduz a identidade que racionaliza as fontes de dominação estrutural" (CASTELLS, 1999, p. 26), mas que, em contrapartida, por estarem próximas do Estado, têm a condição de impulsionar mudanças.

Na conclusão da primeira etapa ficou definida a composição do grupo, de participação heterogênea, o qual deveria conduzir um processo de criação com forte recorte de diversidade. O desenho final contemplou questões de gênero, trabalho informal, raça, minorias, meio ambiente, monitoramento e controle cidadão, pesquisa e desenvolvimento, órgãos governamentais, distribuídos nas cinco regiões brasileiras, de pequeno, médio e grande porte.

Os representantes das organizações foram escolhidos com base no critério de atuação e liderança. Assim sendo, a participação tinha caráter não só de representar a fala de uma dada causa, mas também da contribuição da sua personalidade como agente social.

Há dificuldade em dispor do tempo necessário à etapa de preparação, visto a intensa rotina das organizações. Nesse caso, o processo de co-criação pode ser impactado pelo desnível com o qual os participantes iniciam o trabalho. Alguns representantes da sociedade civil declararam não ter conhecimento prévio suficiente para as primeiras discussões. Não há informações suficientes para detectar onde aparecem as limitações da participação decorrentes da dificuldade em administrar o desnível de informações e a amplitude temática. Não se conseguiu identificar nas falas dos entrevistados referências diretas à contribuição da sua participação, excetuando-se a contribuição de informações diretamente relacionadas ao seu trabalho. Esses não ditos podem significar certa dificuldade em entender sistemicamente todo o processo. 


\subsection{Visualidade}

Na primeira fase, o processo dos Cenários Transformadores não privilegia os recursos de visualização. São reuniões e entrevistas nas quais o foco é a construção de uma base conceitual. $\mathrm{O}$ trabalho é feito principalmente com os gestores do projeto de cenários. $\mathrm{O}$ grande grupo foi preparado para a fase de workshops com a leitura da compilação das entrevistas-diálogo, estruturadas em forma de uma série de recortes dos depoimentos, com panorama geral do entendimento dos participantes sobre os temas que seriam abordados.

$\mathrm{Na}$ segunda fase, a visualidade é explorada tanto para a discussão como para a construção das ideias. A prototipação, com o uso de legos e de vídeos, é usada para encaminhar as ideias discutidas rumo à concretização do projeto. Os paticipantes responderam positivamente a esse estímulo.

\section{CONCLUSÃO}

Ao longo deste artigo, foram apresentados os principais conceitos que cercam a temática da construção dos "Cenários Transformadores" para a sociedade civil. Pela triangulação e interpretação desses dados, é possível analisar os elementos primordiais ao desenvolvimento de ferramenta aplicável pelas organizações da sociedade civil. Nas categorias de análise, observamos que os 'Cenários Transformadores' conseguem atingir os representantes e grupo de trabalho, mas são pouco efetivos em relação a serem reconhecidos como uma ferramenta aplicável nas organizações. Os participantes atestam a importância da atividade, mas não entendem como podem conduzi-la enquanto convocadores.

A condução das forças de poder e liderança dos atores são tratadas com segurança pelos "Cenários Transformadores". Entende-se que a diversidade de atores possibilita o controle das forças, mas em exercícios formados por grupos de representantes da sociedade civil, esse será um desafio constante, tendo em vista a característica de ativistas desses atores.

Os processos visuais são explorados aquém de sua possibilidade. Isso se deve a origem do modelo, que vem da gestão e privilegia reuniões e discussões orais, com pouco uso de outros recursos. Essa é uma fragilidade da construção do modelo, que no trabalho de cenários para a sociedade civil deve ser revisto e reconhecido como um importante motivador, inclusive na fase de preparação, pouco aproveitada pela maioria dos participantes.

As análises mostraram o alto nível de dificuldade em mover os resultados dos cenários para ações práticas nas organizações dos participantes, de forma a multiplicar a capacitação destes em suas organizações. Entre outros possíveis motivos, estão as tarefas cotidianas, que os levam a se absterem desse trabalho em prol da manutenção de suas atividades e os afasta da continuidade do processo.

A proposta para a continuidade deste trabalho é o desenvolvimento de um modelo similar de cenários, a ser aplicado em organização da sociedade civil, tendo esta como principal convocadora.

\section{REFERÊNCIAS}

BASON, C. Leading public sector innovation: co-creating for a better society. Grã Bretanha: The Police Press. 2010.

BUCHANAN, R. Wicked Problems in Design Thinking. Design Issues, Vol. 8, No. 2 pp. 5-21

Published by: The MIT Press. Disponível na internet por http em $<$ http http://www.jstor.org/stable/1511637 >. Acesso em setembro de 2009.

CASTELLS, M. A sociedade em rede. A era da informação: economia, sociedade e cultura. São Paulo: Paz e Terra, v. 1, 1999. 
CASTELLS, M. Redes de indignação e de esperança. Rio de Janeiro: Zahar, 2013c.

CASTELLS, M.; INCE, M. Conversations with Manuel Castells. Wiley, 2003.

DRUCKER, P. F. Inovação e espírito empreendedor. São Paulo: Cengage Learning, 2010.

FREIRE, K.M. Design Estratégico: origens e desdobramentos. Gramado: P\&D, 2014.

KAHANE, A. Planejamento de Cenários Transformadores: trabalhando juntos para mudar o futuro. São Paulo: Senac, 2013.

MANZINI, E. Design para a inovação social e sustentabilidade: comunidades criativas, organizações colaborativas e novas redes projetuais Rio de Janeiro: E-papers, 2008. (Cadernos di Grupo de Altos Estudos; v. 1) 104.

MANZINI, E. Ideas of wellbeing: beyond the rebound effect, paper presented to the sustainable services \& systems: transition towards sustainability. Amsterdam, October 2001 (paper to be published).

MANZINI, E. Scenarios of sustainable wellbeing. Design Philosophy Papers, v. 1, n. 1, 2003. Disponivel na internet por http em < http://www.desphilosophy.com/dpp/dpp_index.html>. Acesso em janeiro de 2015.

MANZINI, E.. Small, local, open and connected. Design for Social Innovation and Sustainability. New York, PARSONS, 2010.

MANZINI, E. The scenario of the multi-local society. In: CHAPMAN. J.; GANT, N. Designers, visionaries plus other stories. London: Earthscan, 2007.

MANZINI, E.; JÉGOU, F. Collaborative services: social innovations and design for sustentainability. Poli Design, 2008.

MANZINI, E.; JÉGOU, F. Scenarios for sustainable household. CIR.IS. Politecnico di Milano, p. 112, 1998.

MANZINI, E. JÉGOU, F. The construction of design-orienting scenarios. Final Report, SusHouse Project, Netherlands, Delft University of Technology, 2000.

MANZINI, E.; STASZOWISK, E. Introduction. public and collaborative. Exploring the intersection of design, social innovation and Public Policy. Desis Network, 2013.

MARGOLIN, V. The idea of design. Cambridge, MA: MIT Press, 1996.

MARGOLIN, V., MARGOLIN, S. Um modelo social de design: questões de prática e pesquisa. Revista Design in Foco, 2004.

MERONI, A. Strategic design: where are we now? Reflection around tha foundations of a recent discipline. Strategic Design Research Journal, v. 1, n. 1, p. 31-38 jul-dez.,2008.

MOUCHREK, N.; KRUCKEN, L. Laboratório de Design. Co-criação e sustentabilidade, uma iniciativa no ensino de design p. 1654-1666. In: Anais do 110 Congresso Brasileiro de Pesquisa e Desenvolvimento em Design Blucher Design Proceedings, v. 1, n. 4. São Paulo: Blucher, 2014.

MURRAY, R. et al. The open book of social innovation. The Young Fundation, Innovating Public Services, 2010. 
REOS PARTNERS. Relatório Cenários Sociedade Civil 2023. São Paulo, 2013. Disponível na internet por http em < http://sociedadecivil2023.org.br/materiais/>. Acesso em 03/01/2014.

RUA, M.G. Análise de políticas públicas: conceitos básicos. 2001.

SOCIEDADE CIVIL 2023. 2013. Disponível na internet por http em < www.reospartners.com. > Acesso em 20/01/2014.

STASZOWSKI E. et al. Reflections on designing for social innovation in the public sector: a case study in New York City. Desis Network, 2013.

TEIXEIRA, E.C. O papel das políticas públicas no desenvolvimento local e na transformação da realidade, AATR-BA, 2002.

ZURLO, F. Design strategico. XXI Secolo. v. IV, Gli spazi e le arti. Roma: Enciclopedia Treccani. 2010. 